\title{
High-performance Work System: A Review Based on Content and Process Perspectives
}

\author{
Shushu Cheng \\ School of Nanjing University of Science and Technology, Nanjing 210000, China \\ chengshushu16@gmail.com
}

Keywords: High-performance Work System, Content Perspective, Process Perspective.

\begin{abstract}
High-performance work system is the core content of strategic human resource management, and scholars at home and abroad have made very rich achievements in this field. This paper mainly reviews the relevant researches of HPWS based on content perspective and process perspective respectively, so as to better understand the mechanism of the impact of HPWS on organizational and individual performance. From the content perspective of HPWS, this paper analyzes the content structure of HPWS, the four perspectives of the relationship between HPWS and organizational performance, and the measuring methods of HPWS. From the process perspective of HPWS, this paper summarizes the differences among different levels of HPWS, and also the measuring methods of HPWS. In the end, this paper builds an integrated research framework for HPWS and makes a prospect of the future research directions of HPWS.
\end{abstract}

\section{Introduction}

More and more human resource researchers and practitioners have found that human resource systems that leverage human capital by acquiring, developing, and motivating the best talent can dramatically improve organizational performance ${ }^{[1]}$.These human resource systems that can improve employee capabilities, commitment, and productivity are often referred to as "high-performance work systems, HPWS" "2]. HPWS is the core content of strategic human resource management. Over the past two decades, scholars at home and abroad have achieved very rich results in research on HPWS and their impact on organization and individual performance. Numerous studies show that organizations using HWPS will have better organizational performance $^{[3]}$.

Bowen and Ostroff (2004) propose that human resources management system has two perspectives: content and process, the content perspective refers to which practices constitute the human resource management system, and the effect of different combinations of practices may be the same; and the process perspective refers to how the human resources management system is designed and implemented. From the perspective of process, Bowen and Ostroff explain how the mechanism of the human resource management system and the role of performance relationships occur, and explain the characteristics of the practice system that promotes performance. The research emphasizes the importance of the human resource management process ${ }^{[4]}$. Similarly, HPWS also have two perspectives, content and process: the content perspective of HPWS focuses 
on the specific human resource practices included in HPWS and how best to combine these practices to achieve synergies Effects, focusing on the relationship between these practices and their organizational and individual performance. This content perspective emphasizes that as long as HPWS includes practices that can improve employee knowledge, skills, and motivation, HPWS will have a positive effect on employee and organizational performance ${ }^{[5]}$.

However, studies have also shown that HPWS have no significant effect on organizational performance $^{[6]}$, in order to clarify the inconsistency of this research result, some scholars put forward the process perspective of HPWS. From the perspective of process, even if the organization has designed a very perfect HPWS, if HPWS cannot be effectively implemented, employees will not be able to perceive, understand, and accept the system set up by the organization, which will reduce the effectiveness of the system ${ }^{[4]}$. However, the process of HPWS's impact on organizational performance is still regarded as a "black box" for strategic human resource management research. In this regard, some scholars have suggested that we should not only study the specific composition of human resources practices of HPWS, but also explore and identify the process of the impact of these human resources practices and the mediator variables among them, so as to define HPWS more accurately. Therefore, this study will review HPWS's relevant research based on HPWS's content perspective and process perspective, so as to better understand the mechanism of HPWS's impact on organizational and individual performance.

\section{High-Performance Work System and Its Differentiation from Related Concepts}

\subsection{The Concept of High-Performance Work System}

Most studies use the narrow definition of HPWS, which emphasizes the organization's strategic objectives through human resource practice activities. HPWS can be seen as a coherent bundle of high-performance work practices (HPWPs) that can create synergies, some of which reinforce each other to improve organizational performance ${ }^{[7]}$. Appelbaum et al. (2000)proposed the classic HPWS "AMO" model, which considers organizational performance as a derivative function of the organization's core element structure, and the organizational structure is composed of the three elements of employees' ability, motivation and participation opportunities to perform their duties. The human resource practices in HPWS should be able to improve these three elements, In other words, HPWS influences the organization's performance through HPWPs that improve employee capabilities, motivation, and opportunities. The "AMO" model is widely cited by the academic community $^{[8]}$.

Chinese scholars Zhang and Li (2015) summed up the connotation of the HPWS on the basis of literature review and proposed that HPWS contains three concepts: (1) Performance, HPWS can improve the organization's performance in a certain way; (2) Work practices, HPWS is a set of HR practices rather than a single practice; (3) Systemic or synergistic effects. In summary, HPWS is a dynamic combination of human resource practices that improve organizational performance by improving employees' abilities, attitudes, and motivations. This dynamic combination can promote synergies between the organization's various performance results ${ }^{[9]}$.

\subsection{Differentiation among High-Performance Work System and Related Concepts}

In addition to high-performance work system, many studies also use concepts such as high-involvement work system and high-commitment work system ${ }^{[10]}$. High-performance, high-involvement, and high-commitment work systems are all combinations of human resource practices, and can bring varying degrees of impact at different levels (individual and organizational 
levels). The purpose of a high-involvement work system is to redesign the work to enhance the employee's sense of responsibility and power, which is often accompanied by an increase in employee work skills and incentives for employee involvement ${ }^{[11]}$. Scholars generally believe that high-commitment work system is a set of human resource practices that enhance the organizational commitment of employees, and it is not the practice of controlling employees and letting employees obey ${ }^{[13,12]}$. Therefore, the high-involvement work system emphasizes the characteristics of employees' self-planning and self-management, the high-commitment work system emphasizes that the system can enhance the employees' organizational commitment, while the high-performance work system emphasizes the high level Performance that the system can bring.

As a result, the differences in high-performance, high-involvement, and high-commitment work systems can be summarized as two points: (1) The focus of the three is not the same, and the connotation of high-performance work system is more extensive, because the high-involvement work system emphasizes the achievement of the organization's goals through the involvement of employees, and the high-commitment work system emphasizes that the organization's goals are achieved by improving the employees' organizational commitment, while the high-performance work system only emphasizes the hope that the system can bring high performance, and does not emphasize the approach taken to obtain high performance; (2) The differences in the emphasis of the three make the contents and measurements of human resource practices different. Due to theoretical differences or confusion, there are also great differences in the concrete measurement of human resource practices in empirical research, even in the same research, there are inconsistencies between the theoretical framework and the specific measurement, this makes researchers tend to think of high-involvement, high-commitment and high-performance work systems as expressing the same meaning. Therefore, in addition to reviewing the research on high-performance work system, this study also includes concepts such as high-involvement, high-commitment work systems, and so on, which are very similar in connotation to high-performance work system.

\section{The Content Perspective of High-Performance Work System}

\subsection{The Content Structure of High-Performance Work System}

The content perspective of HPWS focuses on the specific human resource practices included in HPWS. However, there is still a lot of controversy over which human resource practices constitute HPWS $^{[14]}$. What are the contents that HPWS should contain and what are the structural features it exhibits? The research of this issue is the main focus of HPWS content perspective. Therefore, this section will review the content structure of HPWS based on the literature review. Scholars have not reached a consensus on what human resource practices should be contained in HPWS. Different scholars have different understandings and divisions of the content structure of HPWS, which mainly includes two dimensions, three dimensions and four dimensions.

Huselid (1995) used 968 companies in the United States as the research object and proposed the two-dimensional structure of HPWS: employee skills and organizational structures, and employee motivation. Shaw et al. (2009) took 302 companies in the United States service industry as the research object, and proposed that HPWS include two dimensions: HRM inducements and investments, and expectation-enhancing practices. Chow and Liu (2009) conducted an empirical study on 451 companies in southern China, and concluded that HPWS includes two dimensions: inducement-HR, and involvement-HR.

Fey et al. (2001) conducted an empirical study of 319 companies in the United States and concluded that HPWS should include three dimensions: employee development, compensation/organizational structure, and feedback systems, and concluded that investment in 
human resource practices can improve Organizational performance. Sels et al. (2006) took 416 companies in Belgium as the research object, the study considered that HPWS includes three dimensions of HR flows, rewards, and employee influence. The empirical research conducted by Batt and Colvin (2011) with 93 call centers in the US service industry showed that HPWS includes three dimensions: high involvement work organization practices, long-term incentives (investment and incentive practices), and short-term incentives (performance-enhancing practices).

Bae et al. (2003) conducted an empirical study of 700 companies in the four regions of the Pacific Rim (Korea, Taiwan, Singapore, and Thailand) and proposed that HPWS includes four dimensions of human resource mobility, work systems, reward systems, and employee influence, and the results Showed that HPWS is still effective for organizational performance even under conditions of significant cultural differences.

Based on the above research, it is not difficult to find that the names and contents of HPWS are not the same among different scholars. Therefore, it is difficult to summarize the content structure of HPWS, and it is difficult to compare the content structure of HPWS among different studies. In addition, some scholars do not directly divide the dimensions of HPWS, but directly select different human resources practices to form HPWS. Zhang and Li (2015) used literature research methods to sort out 187 sample documents in the field of HPWS. Among them, 116 papers did not divide the dimensions of HPWS. It is found that the human resource practices contained in HPWS is at least 3 items, with a maximum of 21 items, with an average of 8 items, and different scholars have great differences in defining the content of the same human resource practice.

\subsection{Four Views on the Relationship between High-Performance Work System and Organizational Performance}

For the relationship between HPWS and organizational performance, Martínalcázar et al. (2005) have summarized four different research perspectives: the universal view, the contingency view, the configuration view and the situational view. Next, this section mainly compares these four perspectives. The basic assumption of the universal view is that there are best human resource practices in HPWS, it applies to all kinds of organizations and does not need to consider the influence of background factors ${ }^{[15]}$. The contingency view holds that some background factors will affect the role of HPWS in performance, including three main categories, namely, strategic factors, organizational factors and environmental factors. In other words, background factors will moderate the relationship between HPWS and organizational performance ${ }^{[16]}$. The basic assumption of the configuration view is that different human resource practices in HPWS can be combined in different ways, and the unique effects of the combined model on organizational performance are better than the effect of directly summing up all the individual human resource practices. This point emphasizes the existence of synergy and interdependence between different human resource practices $^{[17]}$. The situational view provides a more comprehensive view that HPWS is considered to be part of the social macro system, and that the environmental context is not only a simple contingency factor, but will interact with the human resource management strategies.

\subsection{Measurement of High-Performance Work System}

There are three main methods of measuring human resource practices: (1) the existence or not of human resource practices (ie, yes or no choices); (2) the coverage of practice (ie, the scope covered by human resource practices); (3) The degree of employee perception. HPWS's content perspective is mainly based on the first method. This method is easy to obtain data and is also relatively easy to analyze. This method is mainly to measure the existence of human resource practices that should be included in HPWS. However, as mentioned in the first part of this chapter, what human resource 
practices should be measured (ie, the HR practices contained in HPWS), scholars are still quite controversial $^{[10]}$. Research shows that the measurement of human resource practices contained in HPWS includes a minimum of 3 items, a maximum of 21 items and an average of 8 items.

\section{The Process Perspective of High-Performance Work System}

\subsection{Different Levels of High-Performance Work System}

The process perspective of HPWS focuses on the implementation process of HPWS. The social information processing theory holds that individuals as an adaptive mechanism, will search for information in the work environment and use this information to guide their perceptions, attitudes and behaviors ${ }^{[18]}$. The process perspective of HPWS believes that each employee may have a unique understanding of human resource practices, they will actively think, judge, and reason about the human resource practices implemented by the organization, instead of directly showing the desired behaviors of the organization. Therefore, the HPWS formulated by the organization is not necessarily consistent with the perceived HPWS of employees. Whether it is consistent and how consistent is essential to the effectiveness of HPWS, this not only means whether the organization's HPWS information can be effectively transmitted from top to bottom, but also whether the organization's strategic goals can be effectively implemented. Previous studies have proposed three levels of HPWS: organizational level, departmental level and employee level, and discussed the relationship between different levels of HPWS. This section will review and sort out the literature on the relationship between different levels of HPWS.

\subsubsection{HPWS at the organizational level and HPWS at the departmental level}

Zhang and Long (2017) used 19 HR managers and 81 department managers as their research objects, and discussed the consistency between HPWS at the organizational level and HPWS at the departmental level. The results of the study showed that the correlation between HPWS at the organizational level and HPWS at the departmental level is not significant, but the sense of human resource responsibility of department managers plays a moderator role between the two. The sense of human resource responsibility of the department manager refers to the perception of the department manager to regard the implementation of the human resource practices as his own responsibility ${ }^{[19]}$. Cunningham and Hyman (1999) also show that the human resource responsibility of the department managers is an important factor that influences whether human resource practice can be implemented effectively. A department manager with a high sense of human resources will spend more time focusing on HPWS information and will frequently communicate with the manager of human resources ${ }^{[20]}$, so that the manager of department will have a better understanding of HPWS at the organizational level. Nishii et al. (2008) also showed that communication can shorten the gap between HPWS at organizational level and departmental level. In addition, Jiang et al. (2013) found that when department managers are more motivated to deal with human resource management issues, or when department managers are more dependent on the information provided by human resource management department managers, their perceptions are more consistent with those of human resource management managers ${ }^{[21]}$, that is, HPWS at the organizational level is more consistent with HPWS at the departmental level. Therefore, there are certain differences between HPWS at the organizational level and HPWS at the departmental level, but the above studies show that there are many moderator variables for such differences, including the sense of human resource responsibility of the department manager, communication and department managers' motivation and so on. 


\subsubsection{HPWS at the departmental level and HPWS at the employee level}

The HPWS at the employee level is the employee's perception of the organization's HPWS. Liao et al. (2009) found that HPWS at the departmental level does not have a significant predictive effect on HPWS at the employee level, and departmental level evaluation of HPWS is significantly better than that of employees ${ }^{[22]}$. In addition, studies have also shown that there is a significant positive correlation between HPWS at the departmental level and HPWS at the employee level ${ }^{[24,23]}$. Zhang and Long (2017) used 81 supervisors and 399 employees as data samples to explore the consistency between HPWS at the departmental level and HPWS at the employee level. The results show that HPWS at the departmental level has a positive effect on HPWS at the employee level, and the impact is stronger among employees with low power distances. Employees with low power distances have lower acceptance of organizational levels and status differences, this group of employees believe that they are not different from their leaders, and they have the right to participate in the decision making ${ }^{[25]}$, and they are more inclined to interact more with leaders, so that this part of the staff will receive more information about HPWS. As a result, the gap between HPWS at the departmental level and HPWS at the employee level is smaller. In addition, Den Hartog et al. (2012) showed that the higher the quality of communication between managers and employees, the more consistent the HPWS at the departmental level and the HPWS at the employee level ${ }^{[26]}$. Jiang et al. (2013) show that when department managers have stronger management abilities in the handing of human resource management affairs, or when the quality of leader-member exchange and the trust of their employees are higher, the HPWS at the departmental level and the HPWS at the employee level are more consistent ${ }^{[21]}$. Therefore, the HPWS at the departmental level and the HPWS at the employee level are not necessarily the same. Researches show that this inconsistency is moderated by some variables, including the power distance, the quality of communication, the management skills of department managers, and the leader-member exchange quality, etc.

In summary, there are differences among HPWS at the organizational level, departmental level, and employee level. That is to say, there are differences in the perception and evaluation of HPWS between managers and employees. These differences will affect the effectiveness of the implementation of HPWS, but the above studies show that there are many variables that can moderate these differences. And these differences and moderator variables are the focus of the process perspective of HPWS.

\subsection{Measurement of High-Performance Work System}

As described in the previous chapter, the measurement of HPWS mainly includes three methods. The process perspective of HPWS is mainly based on the second method (the coverage of practice) and the third method (the degree of employee perception). A few studies adopt the second method, For example, Huselid's measurement of the dimension "employee skills and organizational structures" includes "what percentage of employees can receive formal information sharing". Most studies use the third method, because the improvement of organizational performance by HPWS should be based on employees' perception of these practices. The process perspective of HPWS holds that, there is a big difference between "expectation", "implementation" and "perception" of HPWS.

Bowen and Ostroff (2004) put forward the concept of "strength" of HPWS based on attribution theory and social influence theory, and believed that the concept has three aspects, including distinctness, consistency and consensus. And they proposed that in a strong atmosphere, employees have a common interpretation of the organization's policies, practices, procedures, and goals, and they would have a common understanding of what the organization expects ${ }^{[4]}$. Bowen and Ostroff 
provided some guidance for the specific measurement of these three characteristics, and considered that the scores on these dimensions reflect both the strength of the human resource system and the degree of consistency or difference in employee's perceptions and responses. The concept of HPWS strength is applied by some subsequent researches. For example, an empirical study of hotels in the Netherlands by Sanders et al. (2008) showed that HPWS's distinctness and consistency can increase employees' emotional commitment to the organization ${ }^{[27]}$. The research of Li et al. (2011) on 64 business departments in three hotels in China showed the impact of the distinctness of HPWS on employees' work attitude. The effective perception of the strength of HPWS by employees can promote employees' job satisfaction and work dynamism, and reduce the turnover intentions ${ }^{[28]}$. Therefore, the measurement of HPWS strength is helpful to study how human resource practices can be effective for organizational performance.

\section{Discussion and Future Research Directions}

HPWS is the core content of strategic human resource management, and scholars at home and abroad have made great achievements in this field. This paper first differentiates the concepts of high-performance, high-involvement, and high-commitment work systems. Integrating previous literatures, it is concluded that the high-involvement work system emphasizes the achievement of the organization's goals through the involvement of employees, and the high-commitment work system emphasizes that the organization's goals are achieved by improving the employees' organizational commitment, while the high-performance work system only emphasizes the high performance that the system can bring, and does not emphasize the approach taken to obtain high performance. However, the purpose of all the three is to achieve organizational management goals through human resources practices.

In addition, researches show that HPWS has two perspectives, content and process. The content perspective focuses on the specific human resource practices included in HPWS, and the process perspective emphasizes the design and implementation process of the system. The two perspectives have different focuses, advantages, and disadvantages, which can provide different ideas for the research of HPWS.

For the content perspective of HPWS, the main concern is the content structure of HPWS. Summarizing previous literatures, it is found that different scholars have different divisions of the content structure of HPWS, mainly including two dimensions, three dimensions, and four dimensions. In addition, the relationship between HPWS and organizational performance mainly includes four different research perspectives: the universal view, the contingency view, the configuration view and the situational view. For the measurement of HPWS, there are mainly three methods: (1) the existence or not of human resource practices; (2) the coverage of practices; (3) the degree of employee perceptions. The content perspective of HPWS is mainly based on the first measurement method. The process perspective of HPWS mainly adopts the second and third methods, and for the third method, some scholars have proposed the concept of "strength" of HPWS. And the measurement of HPWS strength helps to study how human resource practices can be effective for organizational performance. In addition, the process perspective of the HPWS shows that the HPWS at the organizational level, departmental level and employee level are not necessarily consistent, and the inconsistency between HPWS at the organizational level and HPWS at the departmental level is moderated by the sense of human resource responsibility of the department manager, communication and department managers' motivation and so on; and the differences between HPWS at the departmental level and HPWS at the employee level are moderated by the power distance, the quality of communication, the management skills of department managers, and the leader-member exchange quality, etc. 
Based on the above summary, this paper builds an integrated framework here (see Fig. 1), organically combining the mature views of the content perspective and the latest progress of the process perspective to help the future research more comprehensively examine the connotation and role of the HPWS. It is suggested that future research can refer to this framework for research design.

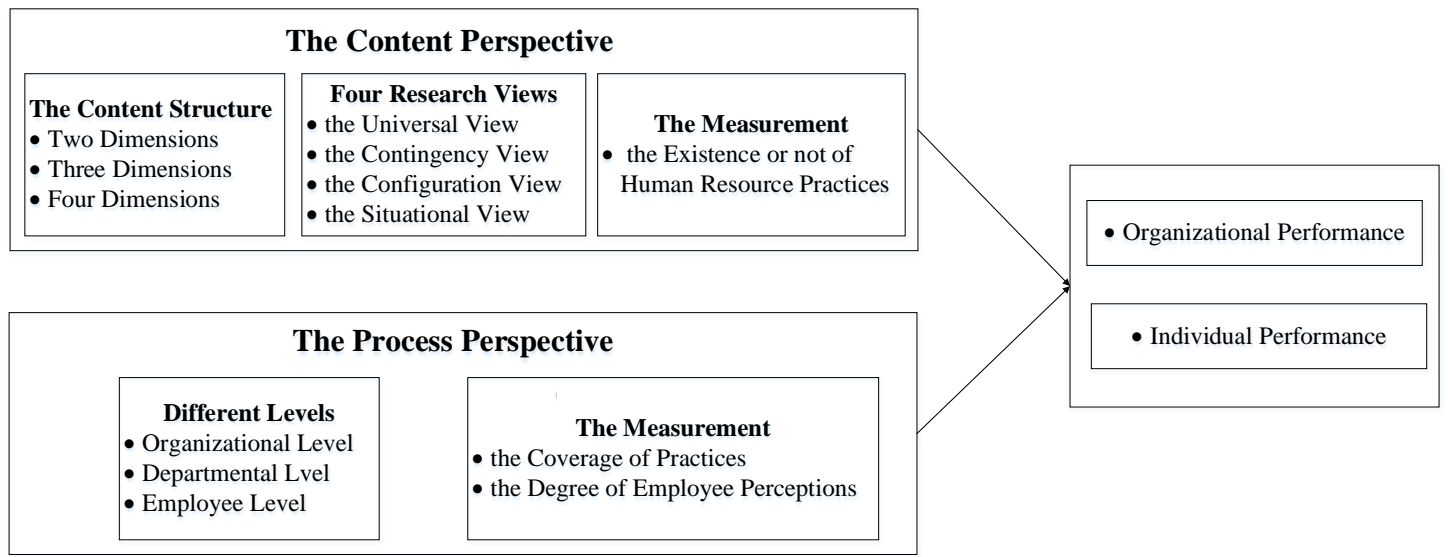

Fig. 1 Integrated research framework for high-performance work system

Finally, for the research of HPWS, this paper proposes two research directions worthy of attention. First of all, according to the content perspective of HPWS, scholars have not reached a consensus on the content structure of HPWS. Researchers usually integrate what they consider as "best practices", thereby ignoring the impact of internal and external environmental factors on them. Different occupation types, different job levels, different workplaces, and different industries all have an impact on the content structure of HPWS. Future research can focus on this area and combine the environmental factors to study the content structure of HPWS. Secondly, there is relatively little research on the process perspective of HPWS. Among them, research on different levels of HPWS provides an important research idea for this perspective. Therefore, future research can be based on this idea for more in-depth research, or explore new ideas to study the implementation process of HPWS.

\section{References}

[1] Posthuma R A, Campion M C, Masimova M, et al. A high performance work practices taxonomy: Integrating the literature and directing future research[J]. Journal of Management, 2013, 39(5): 1184-1220.

[2] Datta D K, Wright P M. Erratum: Human Resource Management and Labor Productivity: Does Industry Matter?[J]. Academy of Management Journal, 2005, 48(1): 135-145.

[3] Jiang K, Lepak D P, Hu J, et al. How Does Human Resource Management Influence Organizational Outcomes? A Meta-Analytic Investigation of Mediating Mechanisms[J]. Academy of Management Journal, 2012, 55(6): 1264-1294.

[4] Bowen D E, Ostroff C. Understanding HRM-Firm Performance Linkages: The Role of the "Strength" of the HRM System[J]. Academy of Management Review, 2004, 29(2): 203-221.

[5] Sanders K, Shipton H, Gomes J F S. Guest Editors' Introduction: Is the HRM Process Important? Past, Current, and Future Challenges[J]. Human Resource Management, 2014, 53(4): 489-503.

[6] Combs J, Liu Y, Hall A, et al. How Much Do High-performance Work Practices Matter? A Meta-analysis of Their Effects on Organizational Performance[J]. Personnel Psychology, 2006, 59(3): 501-528.

[7] Toh S M, Morgeson F P, Campion M A. Human resource configurations: investigating fit with the organizational context[J]. Journal of Applied Psychology, 2008, 93(4): 864-882.

[8] Boselie P, Dietz G, Boon C. Commonalities and contradictions in HRM and performance research[J]. Human Resource Management Journal, 2010, 15(3): 67-94.

[9] Jiang K, Lepak D P, Han K, et al. Clarifying the construct of human resource systems: Relating human resource management to employee performance[J]. Human Resource Management Review, 2012, 22(2): $73-85$.

[10] Jackson S E, Schuler R S, Jiang K. An Aspirational Framework for Strategic Human Resource Management[J]. 
Academy of Management Annals, 2014, 8(1): 1-56.

[11] Guthrie J P. High-Involvement Work Practices, Turnover, and Productivity: Evidence from New Zealand[J]. Academy of Management Journal, 2001, 44(1): 180-190.

[12] Whitener E M. Do "high commitment" human resource practices affect employee commitment? : A cross-level analysis using hierarchical linear modeling[J]. Journal of Management, 2001, 27(5): 515-535.

[13] Arthur J B. Effects of human resource systems on manufacturing performance and turnover[J]. Academy of Management Journal, 1994, 37(3): 670-687.

[14] Paauwe J. HRM and Performance: Achievements, Methodological Issues and Prospects[J]. Journal of Management Studies, 2009, 46(1): 129-142.

[15] Huselid M A. The Impact of Human Resource Management Practices on Turnover, Productivity, and Corporate Financial Performance[J]. Academy of Management Journal, 1995, 38(3): 635-672.

[16] Lepak D P, Taylor M S, Tekleab A G, et al. An examination of the use of high-investment human resource systems for core and support employees[J]. Human Resource Management, 2010, 46(2): 223-246.

[17] Chow I H, Huang J C, Liu S. Strategic HRM in China: Configurations and competitive advantage[J]. Human Resource Management, 2008, 47(4): 687-706.

[18] Salancik G R, Pfeffer J. A social information processing approach to job attitudes and task design[J]. Administrative Science Quarterly, 1978, 23(2): 224-253.

[19] Morrison E W, Phelps C C. Taking Charge at Work: Extrarole Efforts to Initiate Workplace Change[J]. Academy of Management Journal, 1999, 42(4): 403-419.

[20] Pearce J L, Gregersen H B. Task interdependence and extrarole behavior: A test of the mediating effects of felt responsibility [J]. Journal of Applied Psychology, 1991, 76(6): 838-844.

[21] Jiang K, Takeuchi R, Lepak D P. Where do We Go From Here? New Perspectives on the Black Box in Strategic Human Resource Management Research[J]. Journal of Management Studies, 2013, 50(8): 1448-1480.

[22] Liao H, Toya K, Lepak D P, et al. Do They See Eye to Eye? Management and Employee Perspectives of High-Performance Work Systems and Influence Processes on Service Quality[J]. Journal of Applied Psychology, 2009, 94(2): 371-391.

[23] Aryee S, Walumbwa F O, Seidu E Y, et al. Impact of high-performance work systems on individual- and branch-level performance: test of a multilevel model of intermediate linkages[J]. Journal of Applied Psychology, 2012, 97(2): 287-300.

[24] Jensen J M, Patel P C, Messersmith J G. High-performance work systems and job control: : Consequences for anxiety, role overload, and turnover intentions[J]. Journal of Management, 2013, 39(6): 1699-1724.

[25] Lian H, Ferris D L, Brown D J. Does power distance exacerbate or mitigate the effects of abusive supervision? It depends on the outcome[J]. Journal of Applied Psychology, 2012, 97(1): 107-123.

[26] Hartog D N Den, Boon C, Verburg R M, et al. HRM, communication, satisfaction, and perceived performance:A cross-level test[J]. Journal of Management, 2012, 39(6): 1637-1665.

[27] Sanders K, Dorenbosch L, Reuver R De. The impact of individual and shared employee perceptions of HRM on affective commitment: Considering climate strength[J]. Personnel Review, 2008, 37(4): 412-425.

[28] Li X, Frenkel S J, Sanders K. Strategic HRM as process: how HR system and organizational climate strength influence Chinese employee attitudes[J]. International Journal of Human Resource Management, 2011, 22(9): 18251842. 